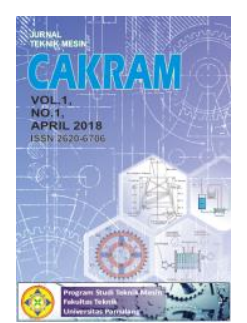

\title{
PENGARUH PANJANG DAN DIAMETER KOLOM UDARA TERHADAP PERFORMA TABUNG IMPEDANSI SEBAGAI ALAT PENENTU CEPAT RAMBAT BUNYI DI UDARA
}

\author{
Sulanjari $^{1}$, Didik Aryanto $^{1,2}$, Adimas wicaksana $^{1}$ \\ ${ }^{1}$ Program Studi Teknik Mesin, Universitas Pamulang, Tangerang selatan, Indonesia, 15417 \\ ${ }^{2}$ Pusat Penelitian Fisika,LIPI, Tangerang selatan, Indonesia, 15310 \\ Email:dosen01182@unpam.ac.id \\ Masuk : 4 Maret 2021 \\ Direvisi : 21 Maret 2021 \\ Disetujui : 8 April 2021
}

\begin{abstract}
Abstrak: Ukuran Tabung impedansi sangat berperan penting dalam menentukan hasil pengukuran dari alat pengukur cepat rambat bunyi di udara. Jika dapat menentukan ukuran tabung impedansi yang paling efektif dapat ditentukan, maka pemanfaatan alat ini bisa berkelanjutan. Metode yang digunakan adalah menentukan nilai kesalahan relatif dari pengukuran. Jika nilai kesalahan relatif yang di dapat kecil maka ketelitiannya semakin tinggi. Tingkat ketelitian tertinggi pengukuran dari alat ini adalah pada diameter paralon 3 inchi dan panjang paralon $1 \mathrm{~m}$ dengan tingkat kesalahan relatif sebesar $0,9 \%$ pada frekuensi 705,21 Hz.. Tingkat ketelitian terendah adalah pada diameter paralon2,5 inchi dan panjang paralon $2 \mathrm{~m}$ dengan dengan tingkat kesalahan relatif sebesar 7,8\% pada frekuensi 705,21 Hz.
\end{abstract}

Kata kunci: tabung impedansi, efektif, kesalahan relatif, panjang paralon, diameter paralon.

\begin{abstract}
The size of the impedance tube was very important in determine the measurement results of the sound measuring device in the air. If it can determine the most effective impedance tube size can be determined, then the usage of this device can be suitable for the next investigation. The used methode was determined to the relative error value of the measurement. If the relative error value is small, then the accuracy was higher. The highest accuration of measurement which at a paralon diameter of 3 inches and a length of paralon $1 \mathrm{~m}$ with a relative error rate of $0.9 \%$ at a frequency of $705.21 \mathrm{~Hz}$. The lowest accuration was at a paralon diameter of 2.5 inches and a length of paralon $2 \mathrm{~m}$ with a relative error rate of $7.8 \%$ at a frequency of $705.21 \mathrm{~Hz}$.
\end{abstract}

Keywords: : impedance tube, effective, relative error, paralon length, paralon diameter 


\section{PENDAHULUAN}

Gelombang bunyi merupakan bagian dari ilmu fisika yang dipelajari diberbagai perguruan tinggi. Gelombang bunyi tidak bisa dilihat, hanya bisa di dengarkan sehingga mempersulit pemahaman mahasiswa. Untuk membantu visualisasi tentang gelombang bunyi maka perlu alat yang bisa menyajikan bentuk nyata dari gelombang bunyi, dengan begitu mahasiswa akan lebih mudah dalam memahami [1]. Bunyi bisa didengar karena ada medium untuk merambat. Bunyi termasuk gelombang longitudinal yaitu arah getarnya sejajar dengan arah rambatnya. [2]. Rentang frekuensi yang bisa didengar telinga manusia adalah 20 sampai dengan $20 \mathrm{kHz}$ [3]. Panjang gelombang bunyi dan cepat rambat bunyi berubah selama gelombang bunyi merambat, tapi untuk frekuensi bernilai tetap[2]. Cepat rambat bunyi udara pada zat padat lebih cepat dibandingkan dengan zat cair. Cepat rambat bunyi di udara adalah $340 \mathrm{~m} / \mathrm{s}$ [4] .

Nilai cepat rambat bunyi di udara yang diperoleh dalam penelitian lubis adalah $(340,33 \pm 1,92) \mathrm{m} / \mathrm{s}$ dengan frekuensi 1-12 $\mathrm{kHz}$ [1]. Sedangkan nilai cepat rambat bunyi diudara yang didapat nurkholis adalah $(341 \pm 0,634) \mathrm{m} / \mathrm{s}$ menggunakan transduser ultrasonik berbasis mikrokontroler ATmega8535[5]. Astuti memperoleh nilai cepat rambat bunyi di udara sebesar $(335,27 \pm 5,80) \mathrm{m} / \mathrm{s}$ menggunakan metode Time of Flight (TOF) dan berbantuan software audacity[6]. Penelitian Sulanjari nilai cepat rambat bunyi di udara yang diperoleh $(349 \pm 13) \mathrm{m} / \mathrm{s}$ dengan koefisien korelasi 99,5\% tingkat akurasinya 97,4\% rentang frekuensi yang digunakan adalah 300 sampai $1000 \mathrm{~Hz}$ [7]. Tujuan pada penelitian ini adalah akan melanjutkan penelitian sulanjari sebelumnya dengan memvariasi panjang dan diameter kolom udara sehingga diperoleh ukuran tabung impedansi yang paling efektif untuk selanjutnya digunakan sebagai alat penentu cepat rambat bunyi di udara. Diameter kolom udara yang digunakan adalah 2,5 inchi dan 3 inchi, sedangkan panjang kolom udara yang digunakan adalah $1 \mathrm{~m}$ dan $2 \mathrm{~m}$ pada frekuensi $576.01 \mathrm{~Hz}, 705,21 \mathrm{~Hz}, 1006,68 \mathrm{~Hz}$.

\section{METODOLOGI}

Alat dan bahan yang digunakan adalah paralon, karpet, generator sinyal, kabel, speaker, mic condensor, amplifier. Langkah berikutnya membuat tabung impedansi, menyelimuti karpet di dalam tabung paralon agar meredam pantulan gelombang bunyi saat pengambilan data. Selanjutnya merangkai semua alat dan bahan seperti gambar1. Menyalakan Generator sinyal dengan frekuensi tertentu, begitu juga amplifier dinyalakan untuk memperkuat amplitudo keluaran generator sinyal. Speaker akan mengeluarkan gelmbang bunyi yang ditangkap mic condensor. Simpul dan perut gelombang bisa dicari dengan menggeser maju mundur batang A-B. Jika Amplitudo maksimum maka itu merupakan perut gelombang. Jika amplitudo minimum maka itu merupakan simpul gelombang.

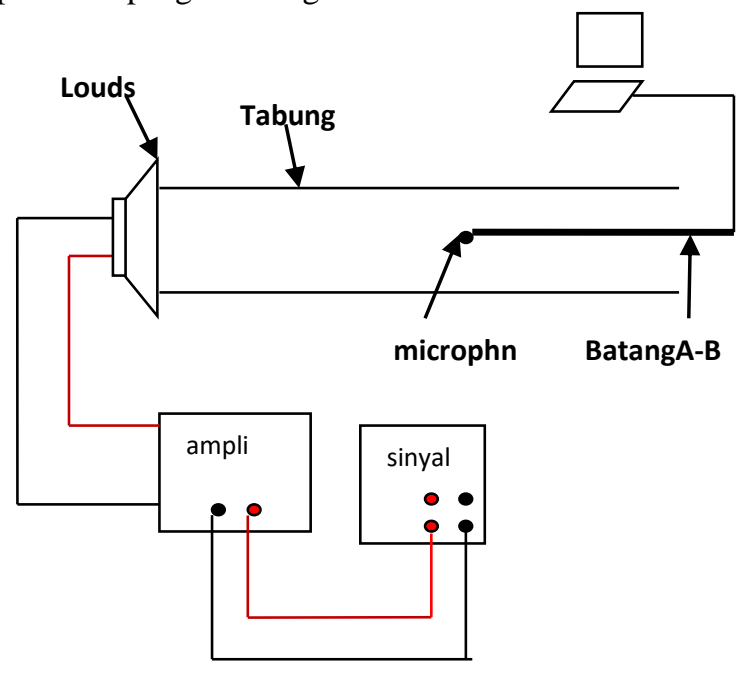

Gambar 1. Desain Penelitian 
Sulanjari dkk, Pengaruh Panjang dan Diameter Kolom Udara Terhadap Performa Tabung Impedansi Sebagai Alat Penentu Cepat Rambat Bunyi di Udara

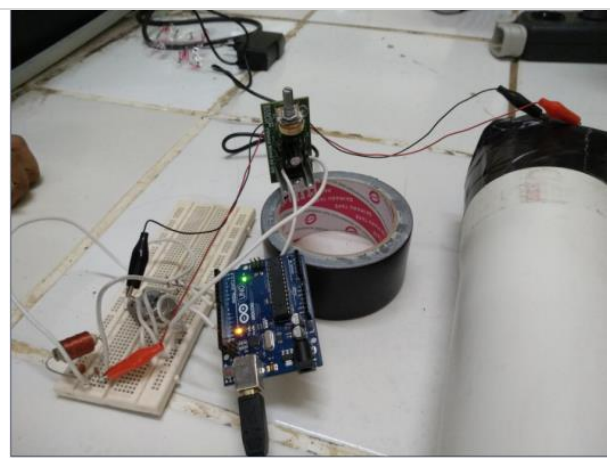

Gambar 2. Rangkaian Alat

Data yang diperoleh adalah $\mathrm{x}$ dan amplitudo. $\mathrm{x}$ merupakan jarak mic terhadap speaker. Dengan mengukur selisih jarak antara posisi mic pada amplitudo maksimum dan minimum, maka diperoleh jarak simpul perut ( $S$ ). Karena jarak simpul perut yang didapat berulang maka untuk menentukan nilai $S$ dan $\Delta S$ menggunakan rumus berikut:

$$
\begin{aligned}
& S=\frac{\sum S}{N} \\
& \Delta S=\frac{1}{N} \sqrt{\frac{N \sum\left(S^{2}\right)-\left(\sum S\right)^{2}}{(N-1)}}
\end{aligned}
$$

Dengan:

$S$ = Jarak simpul-perut gelombang (cm)

$\Delta S=$ ketidakpastian nilai $S(\mathrm{~cm})$

$N$ = Banyaknya perulangan

Untuk menentukan kesalahan relatif $(\mathrm{KR})$ :

$$
K R=\frac{\Delta S}{S} \cdot 100 \%
$$

\section{HASIL DAN PEMBAHASAN}

Berikut ini adalah tampilan software spectra Lab pada frekuensi 1006,68 Hz:

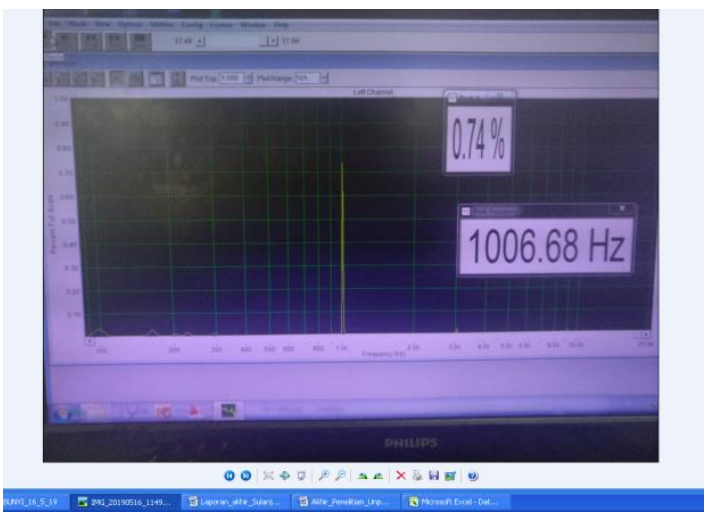

Gambar 3. Tampilan software Spectra Lab 
Sulanjari dkk, Pengaruh Panjang dan Diameter Kolom Udara Terhadap Performa Tabung Impedansi Sebagai Alat Penentu Cepat Rambat Bunyi di Udara

Tabel 1. Kesalahan Relatif dengan variasi diameter ( panjang paralon tetap $1 \mathrm{~m}$ )

\begin{tabular}{|l|c|c|c|}
\hline Frekuensi & Diameter & Jarak simpul-perut & Kesalahan Relatif \\
\hline$(\mathrm{Hz})$ & $($ Inchi $)$ & $(\mathrm{cm})$ & $(\%)$ \\
\hline 576.01 & 2.5 & $13.5 \pm 0.2$ & 1.5 \\
\hline & 3 & $14.3 \pm 0.3$ & 2.1 \\
\hline 705.21 & 2.5 & $11.3 \pm 0.3$ & 2.7 \\
\hline & 3 & $11.3 \pm 0.1$ & 0.9 \\
\hline 1006.68 & 2.5 & $7.7 \pm 0.4$ & 5.2 \\
\hline & 3 & $8.2 \pm 0.3$ & 3.7 \\
\hline
\end{tabular}

Untuk mengetahui pengaruh diameter paralon terhadap performa alat maka panjang paralonnya dibuat tetap dan memvariasikan diameter paralon. Berdasarkan hasil perhitungan di atas dengan panjang paralon tetap yaitu $1 \mathrm{~m}$, dan memvariasikan diameter paralon yaitu 2.5 inchi dan 3 inchi. Pada frekuensi 705,21 Hz dan 1006,68 Hz dengan bertambahnya diameter paralon dapat mengurangi kesalahan relatif dari pengukuran. Sedangkan pada frekuensi 576,01 Hz terjadi kenaikan kesalahan relatif ketika nilai diameternya 3 inchi.

Tabel 2. Kesalahan Relatif dengan variasi diameter ( panjang paralon tetap $2 \mathrm{~m}$ )

\begin{tabular}{|c|c|c|c|}
\hline Frekuensi & Diameter & Jarak simpul-perut & Kesalahan relative \\
\hline$(\mathrm{Hz})$ & $($ Inchi $)$ & $(\mathrm{cm})$ & $(\%)$ \\
\hline 576.01 & 2.5 & $13.4 \pm 0.2$ & 1.5 \\
\hline & 3 & $13.8 \pm 0.3$ & 2.2 \\
\hline 705.21 & 2.5 & $10.2 \pm 0.8$ & 7.8 \\
\hline & 3 & $11.5 \pm 0.3$ & 2.6 \\
\hline 1006.68 & 2.5 & $6.2 \pm 0.2$ & 3.2 \\
\hline & 3 & $8.1 \pm 0.1$ & 1.2 \\
\hline
\end{tabular}

Untuk mengetahui pengaruh diameter paralon terhadap performa alat maka panjang paralonnya dibuat tetap dan memvariasikan diameter paralon Berdasarkan tabel perhitungan di atas dengan panjang paralon tetap yaitu 2 m, dan memvariasikan diameter paralon yaitu 2.5 inchi dan 3 inchi. Pada frekuensi 705,21 Hz dan 1006,68 Hz dengan bertambahnya diameter paralon dapat mengurangi kesalahan relatif dari pengukuran. Sedangkan pada frekuensi 576,01 Hz terjadi kenaikan kesalahan relatif ketika nilai diameternya 3 inchi.

Tabel 3. Kesalahan Relatif dengan variasi panjang (diameter paralon tetap 2.5 inchi)

\begin{tabular}{|c|c|c|c|}
\hline Frekuensi & Panjang Paralon & Jarak simpul-perut & Kesalahan relatif \\
\hline$(\mathrm{Hz})$ & $(\mathrm{m})$ & $(\mathrm{cm})$ & $(\%)$ \\
\hline 576.01 & 1 & $13.5 \pm 0.2$ & 1.5 \\
\hline & 2 & $13.4 \pm 0.2$ & 1.5 \\
\hline 705.21 & 1 & $11.3 \pm 0.3$ & 2.7 \\
\hline & 2 & $10.2 \pm 0.8$ & 7.8 \\
\hline 1006.68 & 1 & $7.7 \pm 0.4$ & 5.2 \\
\hline & 2 & $6.2 \pm 0.2$ & 3.2 \\
\hline
\end{tabular}

Untuk mengetahui pengaruh panjang paralon terhadap performa alat maka diameter paralonnya dibuat tetap dan memvariasikan panjang paralon Berdasarkan tabel perhitungan di atas dengan diameter paralon tetap yaitu 2.5 inchi, dan memvariasikan panjang paralon yaitu $1 \mathrm{~m}$ dan $2 \mathrm{~m}$. Pada frekuensi 705,21 Hz dengan bertambahnya panjang paralon dapat menambah kesalahan relatif dari pengukuran. Sedangkan pada frekuensi 1006,68 Hz terjadi penurunan nilai kesalahan relatif ketika nilai panjang paralonnya $2 \mathrm{~m}$. Kemudian pada frekuensi 576,01 tidak terjadi perubahan kesalahan relatifnya ketika panjang paralon menjadi $2 \mathrm{~m}$. 
Tabel 4. Kesalahan Relatif dengan variasi panjang (diameter paralon tetap 3 inchi)

\begin{tabular}{|c|c|c|c|}
\hline Frekuensi & Panjang Paralon & Jarak simpul-perut & Kesalahan relative \\
\hline$(\mathrm{Hz})$ & $(\mathrm{m})$ & $(\mathrm{cm})$ & $(\%)$ \\
\hline 576.01 & 1 & $14.3 \pm 0.3$ & 2.1 \\
\hline & 2 & $13.8 \pm 0.3$ & 2.2 \\
\hline 705.21 & 1 & $11.3 \pm 0.1$ & 0.9 \\
\hline & 2 & $11.5 \pm 0.3$ & 2.6 \\
\hline 1006.68 & 1 & $8.2 \pm 0.3$ & 3.7 \\
\hline & 2 & $8.1 \pm 0.1$ & 1.2 \\
\hline
\end{tabular}

Untuk mengetahui pengaruh panjang paralon terhadap performa alat maka diameter paralonnya dibuat tetap dan memvariasikan panjang paralon Berdasarkan tabel perhitungan di atas dengan diameter paralon tetap yaitu 3 inchi, dan memvariasikan panjang paralon yaitu $1 \mathrm{~m}$ dan $2 \mathrm{~m}$. Pada frekuensi 576,01 Hz dan 705,21 Hz dengan bertambahnya panjang paralon dapat menambah kesalahan relatif dari pengukuran. Sedangkan pada frekuensi 1006,68 Hz terjadi penurunan nilai kesalahan relatif ketika nilai panjang paralonnya $2 \mathrm{~m}$. Kemudian pada frekuensi 576,01 tidak terjadi perubahan kesalahan relatifnya ketika panjang paralon menjadi $2 \mathrm{~m}$.

\section{KESIMPULAN}

Kesimpulan pada penelitian ini adalah pada frekuensi $576,01 \mathrm{~Hz}$ nilai kesalahan relatif tabung impedansi berdiameter 2,5 inchi lebih kecil dibanding dengan diameter 3 inchi. Sedangkan untuk kesalahan relatif pada panjang kolom udara $1 \mathrm{~m}$ lebih kecil dibanding pada panjang kolom $2 \mathrm{~m}$. Pada frekuensi 705,21 Hz diameter 3 inchi memiliki kesalahan relatif yang lebih kecil dibanding diameter 2,5 inchi. Sedangkan untuk panjang kolom udara $1 \mathrm{~m}$ lebih kecil dibanging yang $2 \mathrm{~m}$. Untuk frekuensi 1006,68 Hz diameter 3 inchi memiliki kesalahan relatif yang lebih kecil dibanding diameter 2,5 inchi. Sedangkan panjang kolom udara $2 \mathrm{~m}$ memiliki kesalahan relatif yang lebih kecil dibanding panjang kolom udara $1 \mathrm{~m}$.

\section{DAFTAR PUSTAKA}

[1]. Lubis, Ashar Muda dan Lizalidiawati., Rancang bangun alat penentu kecepatan bunyi di udara berbasis instrumentasi, Gradien, 2005, 1, 10-15.

[2]. Priyambodo, Tri Kuncoro dan Jati, Bambang Murdaka Eka., 2008, Fisika dasar untuk mahasiswa ilmu komputer dan informatika, Yogyakarta, ANDI.

[3]. Soedojo, Peter., 2004, Fisika dasar, Yogyakarta, ANDI.

[4]. Giancoli, D. C., 2001, Fisika( 5 ed., Vol. 1), Jakarta, Erlangga.

[5]. Nurkholis, Junaidi, dan A. Surtono., Rancang bangun sistem akuisisi data resonansi gelombang bunyi menggunakan transduser ultrasonik berbasisi mikrokontroler ATmega8535, Teori dan aplikasi fisika, 2014, 2,2 .

[6]. Astuti, IAD., Pengembangan alat eksperimen cepat rambat bunyi dalam medium udara dengan menggunakan metode Time of Flight (TOF) dan berbantuan software audacity, UPEJ, 2016, 5, 3.

[7]. Sulanjari., Rancang bangun alat penentu cepat rambat gelombang bunyi di udara menggunakan tabung impedansi, cakram, 2018,1,1. 